\title{
Effects of Adding Tiotropium or Aclidinium as Triple Therapy Using Impulse Oscillometry in COPD
}

\author{
Arvind Manoharan ${ }^{1} \cdot$ Ashley E. Morrison ${ }^{1} \cdot$ Brian J. Lipworth $^{1}$
}

Received: 1 November 2015/Accepted: 26 December 2015/Published online: 13 January 2016

(C) The Author(s) 2016. This article is published with open access at Springerlink.com

\begin{abstract}
Introduction Long-acting muscarinic antagonists confer improvements in spirometry when used in addition to inhaled corticosteroids and long-acting beta-agonists (ICS/ LABA) in COPD. The dual objectives of this proof of concept study were to evaluate trough effects of tiotropium (TIO) or aclidinium (ACL) when used as triple therapy and to assess if impulse oscillometry (IOS) might be more sensitive than spirometry in detecting subtle differences in bronchodilator response.

Methods Patients with moderate to severe COPD already taking ICS/LABA were randomized to receive add-on therapy in cross-over fashion with either TIO $18 \mu \mathrm{g}$ od or ACL $322 \mu \mathrm{g}$ bid for 2-3 weeks each. Measurements of IOS, spirometry, 6-min walk test, St George's Respiratory Questionnaire (SGRQ) and Baseline/Transition Dyspnoea Index (TDI) were made at baseline and after chronic dosing at trough (12 h for ACL and $24 \mathrm{~h}$ for TIO), in addition to domiciliary diurnal spirometry.

Results 13 patients were completed: mean age 69 years, $\mathrm{FEV}_{1} 52 \%$ predicted, $\mathrm{FEV}_{1} / \mathrm{FVC} 0.48$, and R5 $202 \%$ predicted. There were no differences in any visit-based trough IOS or spirometry outcomes comparing TIO versus ACL. Resonant frequency but not total airway resistance at $5 \mathrm{~Hz}$ (R5) significantly improved from baseline with both treatments while peripheral airway resistance (R5-R20) significantly improved with ACL. Visit-based $\mathrm{FEV}_{1}$, and forced and relaxed vital capacity were also significantly
\end{abstract}

Brian J. Lipworth

b.j.lipworth@dundee.ac.uk

1 Scottish Centre for Respiratory Research, Ninewells Hospital and Medical School, University of Dundee,

Dundee DD1 9SY, Scotland, UK improved from baseline with both treatments. There were no significant differences in diurnal $\mathrm{FEV}_{1}$ and $\mathrm{FEV}_{6}$ profiles between treatments. 6-min walk distance and postwalk fatigue significantly improved from baseline with ACL, while post-walk dyspnea improved with TIO. SGRQ symptom score significantly improved to a similar degree with both treatments. TDI significantly improved with ACL versus TIO by 1.54 units.

Conclusion We observed comparable bronchodilator efficacy at trough with TIO and ACL when used as triple therapy in COPD, while IOS was no more sensitive than spirometry.

Keywords COPD - Spirometry - Impulse oscillometry · Tiotropium $\cdot$ Aclidinium

\section{Introduction}

Long-acting muscarinic antagonists (LAMA) are recommended in chronic obstructive pulmonary disease management guidelines [1] as bronchodilator therapy either alone or in combination with long-acting beta-agonists (LABA) and inhaled corticosteroids (ICS). Currently available LAMA include once daily tiotropium (TIO), glycopyrronium (GLYC) and umeclidinium or twice daily aclidinium (ACL). ACL and TIO have similar binding affinities for the M3 receptor and comparable kinetic selectivity for M3 over M2 receptors, while the duration of action for TIO is approximately two-fold longer than that for ACL [2]. For patients with more severe COPD the use of triple therapy with ICS/LABA/LAMA is advocated to improve outcomes including pulmonary function, quality of life, and exacerbations [3-9].

Few studies have however compared different LAMA when used as triple therapy. Once daily use of TIO or 
glycopyrronium versus placebo for 12 weeks as add-on therapy to ICS/LABA conferred similar improvements in spirometry and quality of life in patients with moderate to severe COPD [10]. In a chronic dosing comparison of once daily TIO and twice daily ACL as monotherapy for 2 weeks, the diurnal bronchodilator profile showed a noticeable decline in forced expiratory volume in $1 \mathrm{~s}\left(\mathrm{FEV}_{1}\right)$ between 12 and $24 \mathrm{~h}$ with TIO along with an improvement with ACL after the second evening dose over the same time period, such that the difference was significant [11]. In another study comparing TIO and ACL as monotherapy for 6 weeks, there were similar significant improvements in the $24 \mathrm{~h} \mathrm{FEV}_{1}$ profile with both drugs compared with placebo, while only ACL significantly reduced early morning cough, wheeze, dyspnea, phlegm, and nighttime symptoms versus placebo [12]. In both of these studies [11, 12] there was no significant difference in morning pre dose trough $\mathrm{FEV}_{1}$ when comparing ACL and TIO after chronic dosing.

Spirometry involves a forced expiratory maneuver which may not be the ideal test to detect subtle improvements in airway caliber in COPD due to effort-dependent small airway closure. Impulse oscillometry (IOS) is an effort-independent test performed during normal quiet breathing, thereby obviating expiratory small airway closure [13]. IOS is easier to perform for patients with COPD during tidal breathing and measures the frequency dependence of airway resistance (R) and reactance (X). As previously described [13], IOS can be used to derive total airway resistance at $5 \mathrm{~Hz}$ (R5), central airway resistance at $20 \mathrm{~Hz}$ (R20), peripheral resistance (R5-R20), reactance at $5 \mathrm{~Hz}$ (X5), and area under the reactance curve (AX) as well as the resonant frequency (RF). In one study using IOS comparing TIO and placebo as add-on to ICS/LABA, there was no significant additive improvement on IOS outcomes with chronic dosing, despite a significant improvement in $\mathrm{FEV}_{1}$ [9]. However, we are not aware of any studies which have compared different LAMA as triple therapy using IOS.

The dual objectives of this proof of concept study were to evaluate the effects of TIO or ACL at trough when used as add-on therapy to pre-existing ICS/LABA and also to assess whether impulse oscillometry (IOS) might be more sensitive than spirometry in detecting subtle differences in bronchodilator efficacy. We also used domiciliary spirometry measurements to follow diurnal changes in airway caliber at steady state during each randomized treatment period.

\section{Methods}

\section{Study Participants}

Inclusion criteria were male or female volunteers aged 40-80 years with moderate to severe COPD on ICS/
LABA, FEV $130-80 \%$ and smoking history $\geq 10$ packyears. Exclusion criteria were other significant respiratory diseases; a COPD exacerbation or respiratory tract infection requiring systemic steroids, and/or antibiotics within 1 month ( 3 months if hospitalization was required) of the study commencement. The East of Scotland Research Ethics Service granted ethical approval (Ref: 13/ES/0122), and all patients provided written informed consent.

\section{Study Design}

We carried out a randomized, open-label, cross-over study (Fig. 1). Previously prescribed LAMA were stopped at the screening visit. After a 1- to 2-week period on ICS/LABA, patients were randomized to either ACL (Eklira Genuair, Astra Zeneca, Luton, UK) $322 \mu \mathrm{g}$ bid or TIO (Spiriva HandiHaler, Boehringer, Bracknell, UK) $18 \mu \mathrm{g}$ bid. Following the run-in period, at visit 1 , baseline measurements were recorded. After 2-3 weeks on the study inhaler, participants returned to the department for visit 2. All measurements were taken at trough (i.e., $12 \mathrm{~h}$ post dose for ACL and ICS/LABA and $24 \mathrm{~h}$ post dose for TIO). Participants attended the department the same time during each study visit. After the first treatment period, participants entered a wash-out period of 1-2 weeks. The same process was repeated with the other study inhaler after cross-over.

\section{Primary and Secondary Outcomes}

The primary outcome was change in trough R5 from baseline after chronic dosing. Secondary outcomes included change from baseline in the remaining IOS variables

(R20, R5-R20, X5, RF and AX), spirometry including $\mathrm{FEV}_{1}$, forced mid-expiratory flow between 25 and $75 \%$ of forced vital capacity $\left(\mathrm{FEF}_{25-75}\right)$, forced vital capacity (FVC), relaxed vital capacity (RVC), 6-min walk test (6MWT), domiciliary PiKo-6 measurements for FEV ${ }_{1}$ and $\mathrm{FEV}_{6}$, St George's Respiratory Questionnaire (SGRQ) and Baseline/Transition Dyspnoea Index (BDI-TDI).

\section{Measurements}

Impulse oscillometry (Masterscreen IOS, Höchberg, Germany) was performed in triplicate according to the manufacturer's instructions. Spirometry was performed using a SuperSpiro (Micro Medical Ltd, Chatham, Kent, UK). Domiciliary $\mathrm{FEV}_{1} \& \mathrm{FEV}_{6}$ measurements were recorded using a handheld PiKo-6 monitor (n-Spire Health, Longmont, CO, USA). Domiciliary PiKo-6 measurements were recorded at trough for both drugs; and after each morning and evening dose of ACL (i.e., $2 \mathrm{~h}$ post dose); or at corresponding times after each morning dose of TIO (i.e., 2 and $14 \mathrm{~h}$ post dose). 


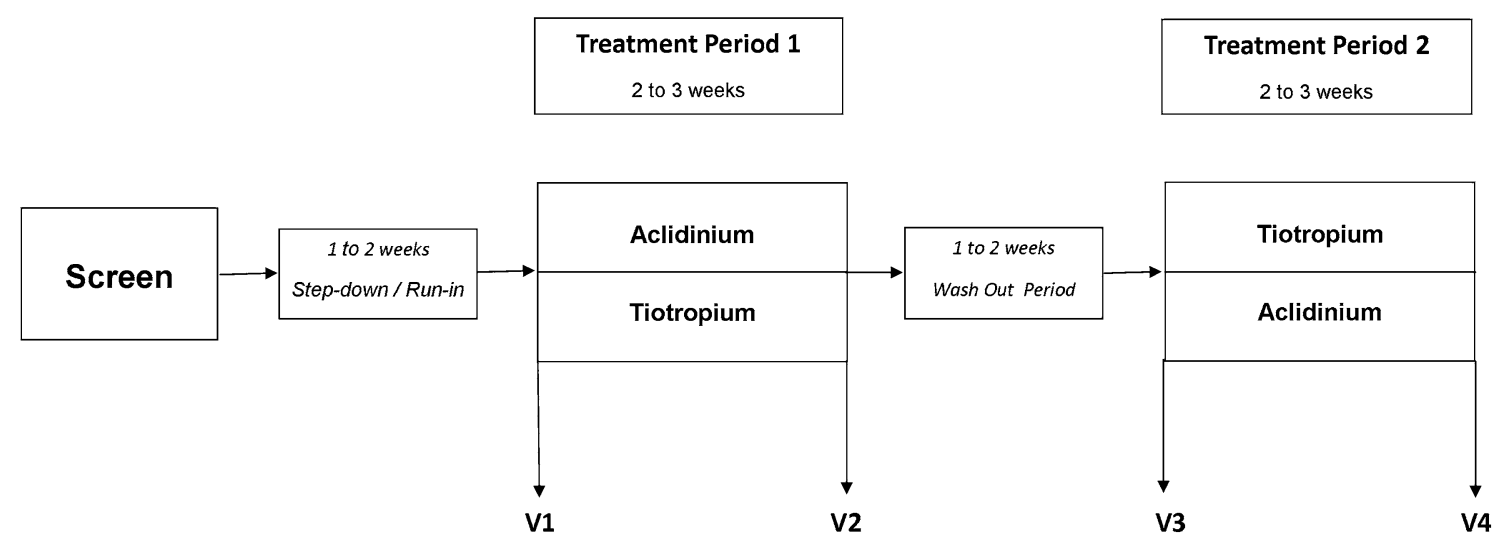

Fig. 1 After a 1- to 2-week run-in, patients received either tiotropium $18 \mu \mathrm{g}$ od or aclidinium $322 \mu \mathrm{g}$ bid for 2-3 weeks each with a 1- to 2-week wash-out in between. Baseline values were measured at Visit 1/3 and after chronic dosing at Visit 2/4

\section{Statistical Analysis}

The study was powered at $80 \%$ to detect a $0.1 \mathrm{kPa} \mathrm{L}^{-1} \mathrm{~s}$ difference in the primary outcome of trough $\mathrm{R} 5$, assuming a within subject standard deviation of $0.13 \mathrm{kPa} \mathrm{L}^{-1} \mathrm{~s}$, and an alpha error of 0.05 (two-tailed). Data were first examined for normality of distribution. Paired Students $t$-tests were used to compare between treatment effects at either baseline and after each chronic dosing, as well as within treatment effects comparing baseline versus chronic dosing. Repeated measures analysis of variance was used to assess the diurnal profile from serial domiciliary $\mathrm{FEV}_{1}$ and $\mathrm{FEV}_{6}$ measurements using the average from the last week of each randomized treatment period and the last week of each baseline.

\section{Results}

Thirteen patients were completed per protocol (Fig. 2): age 69 years, 10 males, and mean of 47 pack-years. Postbronchodilator $\mathrm{FEV}_{1}$ was $52 \%$ predicted with $10 \%$ reversibility, $\mathrm{FEV}_{1} / \mathrm{FVC}$ ratio was 0.48 , and $\mathrm{R} 5 \%$ was $202 \%$ predicted. Nine patients were taking fluticasone/ salmeterol, 3 budesonide/formoterol, and 1 beclomethasone/formoterol, with a mean beclomethasone equivalent dose of $1000 \mu$ day $^{-1} .11$ patients were taking LAMA: 8 with TIO, 2 with ACL, and 1 with glycopyrronium.

Baseline values prior to randomized treatments were not significantly different, and there were also no significant differences in baselines according to visit sequence. There were no differences in any visit-based trough IOS or spirometry outcomes comparing TIO versus ACL (Table 1; Fig. 3). Resonant frequency (RF) but not total airway resistance at $5 \mathrm{~Hz}$ (R5) significantly improved from baseline within both treatments, while peripheral airway resistance (R5-R20) significantly improved with ACL

\section{CONSORT Flow Diagram}

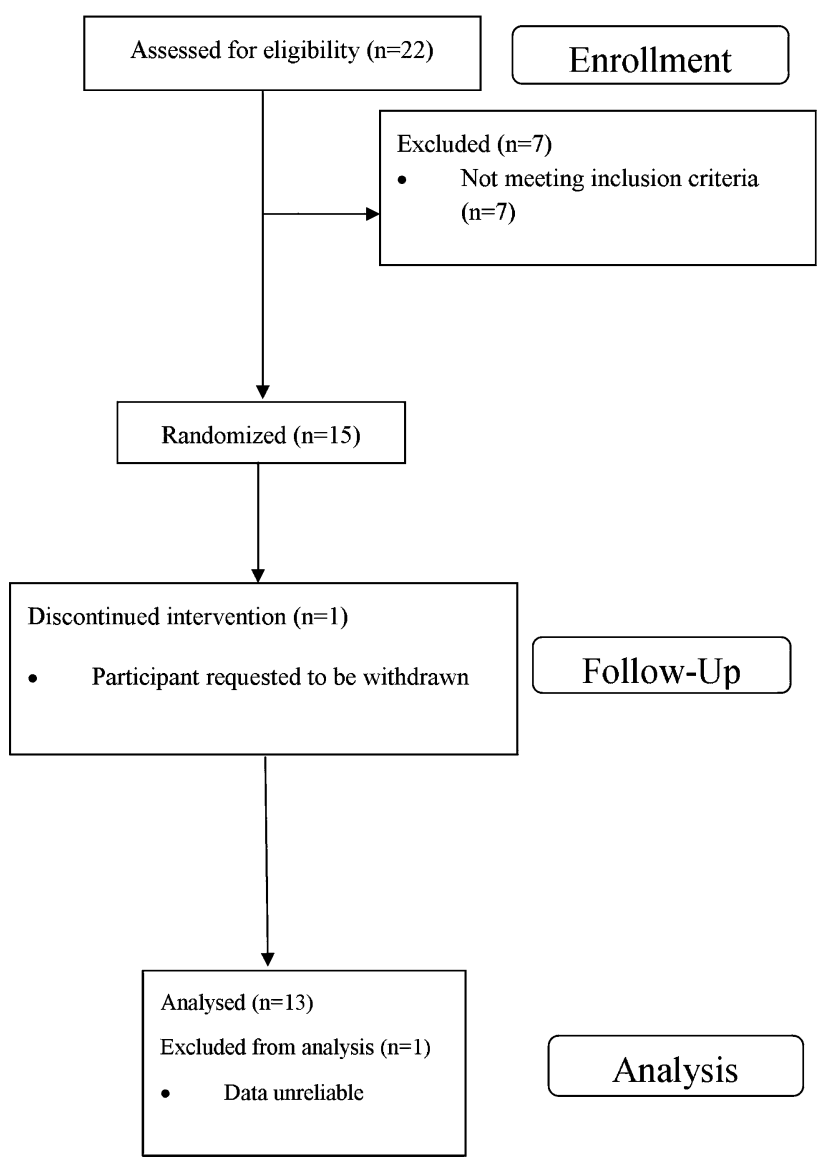

Fig. 2 CONSORT diagram showing the flow of participants through the study

(Tables 2, 3). Visit-based $\mathrm{FEV}_{1}, \mathrm{FVC}$, and RVC were also significantly improved from baseline within both treatments (Tables 2,3). There were no significant differences between treatments at any time points during the diurnal $\mathrm{FEV}_{1}$ and $\mathrm{FEV}_{6}$ profiles (Fig. 4). 
There were no significant differences between treatments for the 6-min walk test (Table 1). Six-min walk distance and post-walk fatigue significantly improved from baseline with ACL, while post-walk dyspnea improved with TIO (Tables 2, 3). Post-walk heart rate and oxygen saturation were not significantly altered by either treatment (Fig. 5).

SGRQ symptom score significantly improved with both drugs from baseline, but there was no difference between treatments total or symptoms score (Tables 1, 2, 3). Mean BDI was 6.54, while TDI was significantly improved by ACL (1.0) versus TIO (-0.54): mean difference 1.54 (95\% CI 0.39-2.69), $P=0.013$.

\section{Discussion}

The results of this proof of concept study showed no significant differences between randomized treatments in any IOS or spirometry outcomes measured at trough after chronic dosing with TIO and ACL when used as triple therapy in patients with COPD. We found no significant difference between treatments in the primary outcome of
R5, although neither drug produced any significant improvements in R5 from baseline. Within the power constraints of the sample size, we cannot exclude the possibility that we may have missed a difference in R5 smaller than $0.1 \mathrm{kPa} \mathrm{L}^{-1} \mathrm{~s}$, which we considered to be a clinically important difference. Other IOS outcomes including R20, X5, and AX were not significantly improved from baseline with either drug from baseline. Nonetheless, we showed that both treatments produced comparable significant improvements from baseline in RF, while ACL also produced a significant improvement in R5-R20. However, the clinical relevance of small changes in IOS outcomes in COPD is uncertain as there are currently no published data with regard to minimal important differences. In one cross-sectional study in COPD patients, peripheral airway resistance correlated with $\mathrm{FEV}_{1}$ and $\mathrm{FEF}_{25-75}$ but not with the Medical Research Council (MRC) dyspnea score [14]. In a baseline cross-sectional analysis of the ECLIPSE study in COPD, IOS was found to be reproducible and was able to define the severity of disease according to global initiative for chronic obstructive lung disease (GOLD) status [15].
Table 1 Change from baseline for aclidinium versus tiotropium

\begin{tabular}{|c|c|c|c|c|}
\hline Parameter & Aclidinium & Tiotropium & Difference $(95 \% \mathrm{CI})$ & $P$ value \\
\hline $\mathrm{FEV}_{1}(\mathrm{~L})$ & 0.11 & 0.15 & $-0.04(-0.13,0.05)$ & 0.36 \\
\hline FVC (L) & 0.28 & 0.24 & $0.03(-0.16,0.23)$ & 0.72 \\
\hline $\mathrm{FEF}_{25-75}\left(\mathrm{~L} \mathrm{~s}^{-1}\right)$ & 0.02 & 0.06 & $-0.04(-0.10,0.01)$ & 0.13 \\
\hline RVC (L) & 0.30 & 0.22 & $0.08(-0.12,0.28)$ & 0.39 \\
\hline $\mathrm{RVC} / \mathrm{FVC}$ & 0.01 & -0.05 & $0.06(-0.09,0.21)$ & 0.38 \\
\hline $\mathrm{R} 5\left(\mathrm{kPa} \mathrm{L}^{-1} \mathrm{~s}\right)$ & -0.07 & -0.03 & $-0.04(-0.12,0.04)$ & 0.29 \\
\hline $\mathrm{R} 20\left(\mathrm{kPa} \mathrm{L}^{-1} \mathrm{~s}\right)$ & -0.01 & -0.02 & $0.01(-0.05,0.06)$ & 0.80 \\
\hline $\mathrm{R} 5-\mathrm{R} 20\left(\mathrm{kPa} \mathrm{L}^{-1} \mathrm{~s}\right)$ & -0.06 & -0.01 & $-0.05(-0.11,0.02)$ & 0.13 \\
\hline $\mathrm{X} 5\left(\mathrm{kPa} \mathrm{L}^{-1} \mathrm{~s}\right)$ & 0.03 & 0.05 & $-0.02(-0.09,0.06)$ & 0.62 \\
\hline $\mathrm{RF}(\mathrm{Hz})$ & -2.22 & -2.77 & $0.54(-2.90,3.99)$ & 0.74 \\
\hline $\mathrm{AX}\left(\mathrm{kPa} \mathrm{L}^{-1}\right)$ & -0.70 & -0.55 & $-0.15(-0.84,0.54)$ & 0.65 \\
\hline \multicolumn{5}{|l|}{$6 \mathrm{MWT}$} \\
\hline Distance (m) & 36 & 9 & $27(-2,56)$ & 0.07 \\
\hline Post-walk oxygen saturation (\%) & 0 & 0 & $0(-2,2)$ & 0.93 \\
\hline Post-walk heart rate (bpm) & 3 & 1 & $2(-2,6)$ & 0.36 \\
\hline Post-walk dyspnoea (Borg scale) & -0.6 & -0.7 & $0.1(-0.6,0.7)$ & 0.79 \\
\hline Post-walk fatigue (Borg scale) & -0.5 & -0.3 & $-0.2(-0.6,0.2)$ & 0.34 \\
\hline \multicolumn{5}{|l|}{ SGRQ } \\
\hline Symptoms score & -7.35 & -7.31 & $-0.03(-5.66,5.59)$ & 0.99 \\
\hline Total score & -0.97 & -2.35 & $1.38(-1.85,4.61)$ & 0.37 \\
\hline
\end{tabular}

Mean values for change from baseline are shown each drug as well as the difference between the drugs $F E V_{1}$ forced expiratory volume in $1 \mathrm{~s}, F V C$ forced vital capacity, $F E F_{25-75}$ forced mid-expiratory flow between 25 and $75 \%$ of forced vital capacity, $R V C$ relaxed vital capacity, $R 5$ total airway resistance at $5 \mathrm{~Hz}, R 20$ central airway resistance at $20 \mathrm{~Hz}, R 5-R 20$ peripheral airway resistance as the difference between $5 \mathrm{~Hz}$ and $20 \mathrm{~Hz}, R F$ resonant frequency, $X 5$ reactance at $5 \mathrm{~Hz}, A X$ reactance area, 6MWT 6-min walk test, bpm beats per minute, SGRQ St George's Respiratory Questionnaire 

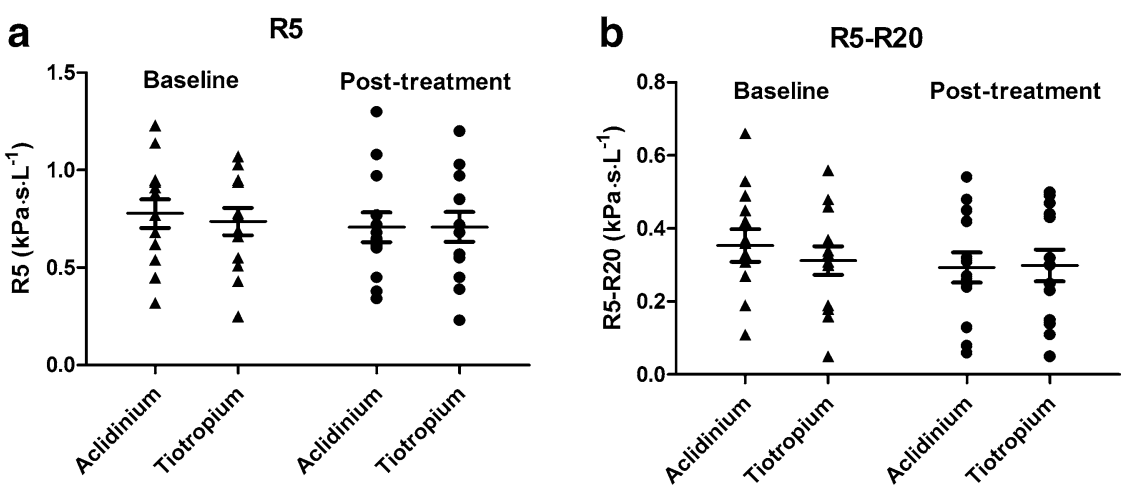

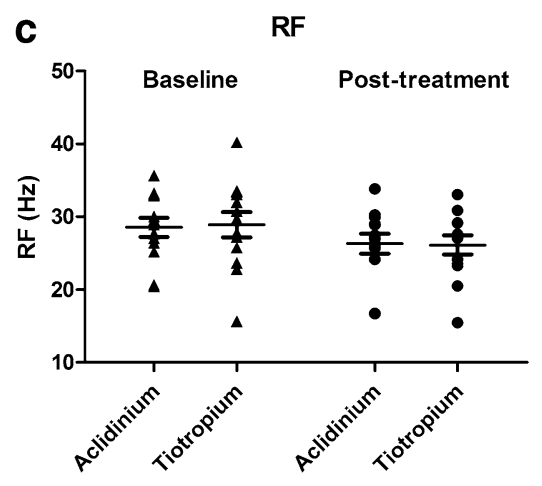

Fig. 3 Effects on impulse oscillometry outcomes at baseline and post-treatment with either tiotropium or aclidinium. Data are depicted for individuals as well as means and SEM. a $R 5$ total airway resistance b $R 5-R 20$ peripheral airway resistance c $R F$ resonant frequency. There were significant improvements from baseline in RF with aclidinium $(P<0.05)$ and tiotropium $(P<0.01)$, and in R-20 with tiotropium $(P<0.05)$. There were no significant differences between tiotropium and aclidinium in any oscillometry outcomes
Table 2 Within aclidinium: baseline versus post-treatment

\begin{tabular}{|c|c|c|c|c|}
\hline Parameter & Baseline & Post-aclidinium & Difference $(95 \% \mathrm{CI})$ & $P$ value \\
\hline $\mathrm{FEV}_{1}(\mathrm{~L})$ & 1.21 & 1.32 & $0.11(0.03,0.18)$ & 0.009 \\
\hline FVC (L) & 2.67 & 2.95 & $0.28(0.05,0.50)$ & 0.02 \\
\hline FEF25-75 $\left(\mathrm{L} \mathrm{s}^{-1}\right)$ & 0.46 & 0.48 & $0.02(-0.04,0.08)$ & 0.50 \\
\hline RVC (L) & 3.12 & 3.43 & $0.30(0.19,0.42)$ & $<0.0001$ \\
\hline $\mathrm{RVC} / \mathrm{FVC}$ & 1.17 & 1.18 & $0.01(-0.08,0.10)$ & 0.76 \\
\hline $\mathrm{R} 5\left(\mathrm{kPa} \mathrm{L}^{-1} \mathrm{~s}\right)$ & 0.78 & 0.71 & $-0.07(-0.15,0.01)$ & 0.07 \\
\hline $\mathrm{R} 20\left(\mathrm{kPa} \mathrm{L}^{-1} \mathrm{~s}\right)$ & 0.42 & 0.41 & $-0.01(-0.04,0.03)$ & 0.61 \\
\hline $\mathrm{R} 5-\mathrm{R} 20\left(\mathrm{kPa} \mathrm{L}^{-1} \mathrm{~s}\right)$ & 0.35 & 0.29 & $-0.06(-0.11,-0.01)$ & 0.02 \\
\hline $\mathrm{X} 5\left(\mathrm{kPa} \mathrm{L}^{-1} \mathrm{~s}\right)$ & -0.38 & -0.34 & $0.03(-0.04,0.11)$ & 0.36 \\
\hline $\mathrm{RF}(\mathrm{Hz})$ & 28.54 & 26.32 & $-2.22(-4.37,-0.08)$ & 0.04 \\
\hline $\mathrm{AX}\left(\mathrm{kPa} \mathrm{L}^{-1}\right)$ & 4.29 & 3.58 & $-0.71(-1.49,0.07)$ & 0.07 \\
\hline \multicolumn{5}{|l|}{$6 \mathrm{MWT}$} \\
\hline Distance $(\mathrm{m})$ & 406 & 442 & $36(1,70)$ & 0.045 \\
\hline Post-walk oxygen saturation (\%) & 91 & 92 & $0(-2,2)$ & 0.73 \\
\hline Post-walk heart rate (bpm) & 76 & 79 & $3(0,6)$ & 0.08 \\
\hline Post-walk dyspnoea (Borg scale) & 2.7 & 2.2 & $-0.6(-1.2,0.1)$ & 0.08 \\
\hline Post-walk fatigue (Borg scale) & 2.2 & 1.7 & $-0.5(-1.0,0.0)$ & 0.04 \\
\hline \multicolumn{5}{|l|}{ SGRQ } \\
\hline Symptoms score & 45.10 & 37.76 & $-7.35(-14.12,-0.57)$ & 0.04 \\
\hline Total score & 36.75 & 35.78 & $-0.97(-4.51,2.57)$ & 0.56 \\
\hline
\end{tabular}

Mean values are shown

$F E V_{1}$ forced expiratory volume in $1 \mathrm{~s}, F V C$ forced vital capacity, $F E F_{25-75}$ forced mid-expiratory flow between 25 and $75 \%$ of forced vital capacity, $R V C$ relaxed vital capacity, $R 5$ total airway resistance at $5 \mathrm{~Hz}, R 20$ central airway resistance at $20 \mathrm{~Hz}, R 5-R 20$ peripheral airway resistance as the difference between $5 \mathrm{~Hz}$ and $20 \mathrm{~Hz}, R F$ resonant frequency, $X 5$ reactance at $5 \mathrm{~Hz}, A X$ reactance area, $6 M W T$ 6-min walk test, $b p m$ beats per minute, $S G R Q$ St George's Respiratory Questionnaire
We are aware of only one other clinical trial evaluating triple therapy in COPD using IOS. In that study, Williamson et al. enrolled patients with severe COPD (FEV $42 \%$ ) comparing 2 weeks of TIO and placebo as add-on to ICS/LABA [9]. IOS outcomes including R5, R20, and X5 were not significantly different after 2 weeks of treatment despite a significant improvement in $\mathrm{FEV}_{1}$. This disconnect between improvements in $\mathrm{FEV}_{1}$ but not $\mathrm{R} 5$ in response to TIO after 2 weeks is consistent with our current findings. Moreover, the mean R5 at baseline on ICS/LABA prior to TIO reported by Williamson et al. was $0.7 \mathrm{kPa} \mathrm{L}^{-1} \mathrm{~s}$ which is similar to baseline $\mathrm{R} 5$ values in our patients. 
Table 3 Within tiotropium: baseline versus post-treatment

\begin{tabular}{|c|c|c|c|c|}
\hline Parameter & Baseline & Post-tiotropium & Difference $(95 \% \mathrm{CI})$ & $P$ value \\
\hline $\mathrm{FEV}_{1}(\mathrm{~L})$ & 1.20 & 1.35 & $0.15(0.10,0.20)$ & $<0.0001$ \\
\hline FVC (L) & 2.73 & 2.97 & $0.24(0.10,0.39)$ & 0.003 \\
\hline FEF25-75 $\left(\mathrm{L} \mathrm{s}^{-1}\right)$ & 0.47 & 0.53 & $0.06(0.02,0.10)$ & 0.004 \\
\hline RVC (L) & 3.22 & 3.44 & $0.22(0.04,0.41)$ & 0.02 \\
\hline $\mathrm{RVC} / \mathrm{FVC}$ & 1.23 & 1.18 & $-0.05(-0.16,0.06)$ & 0.32 \\
\hline $\mathrm{R} 5\left(\mathrm{kPa} \mathrm{L}^{-1} \mathrm{~s}\right)$ & 0.74 & 0.71 & $-0.03(-0.09,0.03)$ & 0.30 \\
\hline $\mathrm{R} 20\left(\mathrm{kPa} \mathrm{L}^{-1} \mathrm{~s}\right)$ & 0.42 & 0.41 & $-0.01(-0.04,0.02)$ & 0.36 \\
\hline $\mathrm{R} 5-\mathrm{R} 20\left(\mathrm{kPa} \mathrm{L}^{-1} \mathrm{~s}\right)$ & 0.31 & 0.30 & $-0.01(-0.07,0.04)$ & 0.58 \\
\hline $\mathrm{X} 5\left(\mathrm{kPa} \mathrm{L}^{-1} \mathrm{~s}\right)$ & -0.37 & -0.33 & $0.05(-0.01,0.11)$ & 0.12 \\
\hline $\mathrm{RF}(\mathrm{Hz})$ & 28.90 & 26.13 & $-2.77(-4.58,-0.96)$ & 0.006 \\
\hline $\mathrm{AX}\left(\mathrm{kPa} \mathrm{L}^{-1}\right)$ & 4.21 & 3.66 & $-0.55(-1.16,0.05)$ & 0.07 \\
\hline \multicolumn{5}{|l|}{$6 \mathrm{MWT}$} \\
\hline Distance $(\mathrm{m})$ & 429 & 437 & $9(-13,30)$ & 0.40 \\
\hline Post-walk oxygen saturation (\%) & 92 & 93 & $0(-1,2)$ & 0.64 \\
\hline Post-walk heart rate (bpm) & 75 & 76 & $1(-2,4)$ & 0.49 \\
\hline Post-walk dyspnoea (Borg scale) & 2.8 & 2.1 & $-0.7(-1.2,-0.1)$ & 0.03 \\
\hline Post-walk fatigue (Borg scale) & 2.4 & 2.1 & $-0.3(-0.8,0.2)$ & 0.21 \\
\hline \multicolumn{5}{|l|}{ SGRQ } \\
\hline Symptoms score & 47.34 & 40.03 & $-7.31(-14.62,0.00)$ & 0.05 \\
\hline Total score & 38.85 & 36.50 & $-2.35(-5.71,1.02)$ & 0.15 \\
\hline
\end{tabular}

Mean values are shown

$F E V_{1}$ forced expiratory volume in $1 \mathrm{~s}, F V C$ forced vital capacity, $F E F_{25-75}$ forced mid-expiratory flow between 25 and $75 \%$ of forced vital capacity, $R V C$ relaxed vital capacity, $R 5$ total airway resistance at $5 \mathrm{~Hz}, R 20$ central airway resistance at $20 \mathrm{~Hz}, R 5-R 20$ peripheral airway resistance as the difference between $5 \mathrm{~Hz}$ and $20 \mathrm{~Hz}, R F$ resonant frequency, $X 5$ reactance at $5 \mathrm{~Hz}, A X$ reactance area, $6 M W T$ 6-min walk test, $b p m$ beats per minute, $S G R Q$ St George's Respiratory Questionnaire
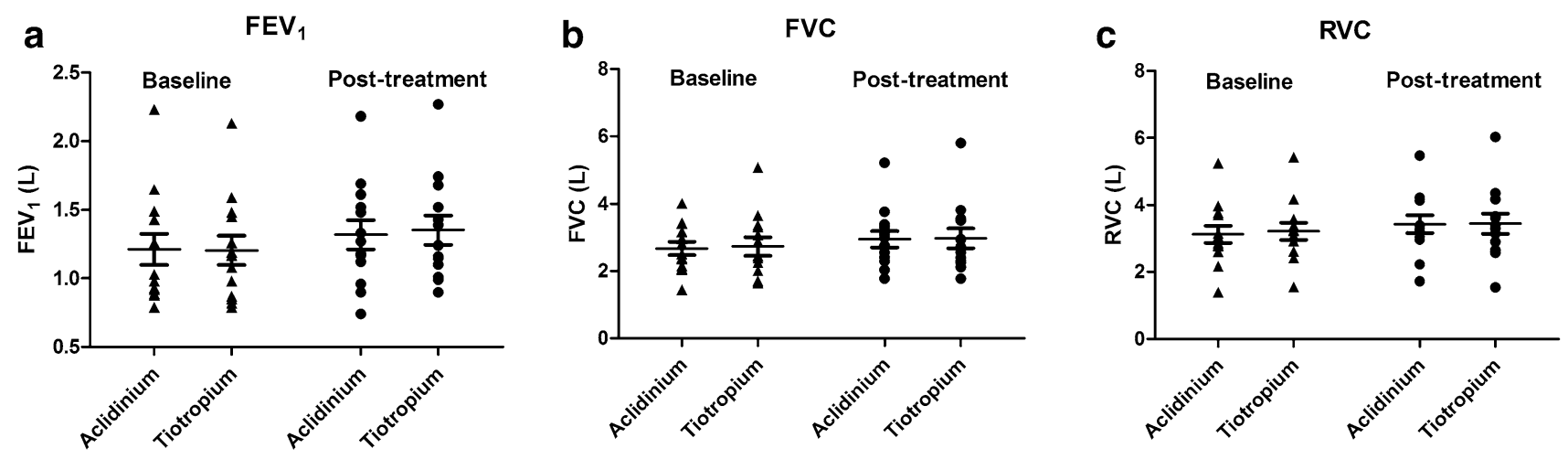

Fig. 4 Effects on spirometry outcomes at baseline and post-treatment with either tiotropium or aclidinium. Data are depicted for individuals as well as means and SEM. a $F E V_{l}$ forced expiratory volume in $1 \mathrm{~s}$ b $F V C$ forced vital capacity c $R V C$ relaxed vital capacity. There were significant improvements from baseline for $\mathrm{FEV}_{1}$ within aclidinium

Perhaps performing a further evaluation using a full 24-h profile with serial IOS as an area under the curve (AUC) might be able to detect more subtle differences in airway caliber which we did not observe on a single trough measurement.
$(P<0.01)$ and tiotropium $(P<0.0001)$, for $\mathrm{FVC}$ within aclidinium $(P<0.05)$ and tiotropium $(P<0.01)$, and for RVC within aclidinium $(P<0.0001)$ and tiotropium $(P<0.05)$. There were no significant differences between tiotropium and aclidinium in any spirometry outcomes

Whole-body plethysmography is alternative effort-independent test using a panting maneuver which can measure airway resistance (or its reciprocal as conductance) but is more difficult and time consuming to perform than IOS. Singh et al. reported on a comparison of fluticasone/ 


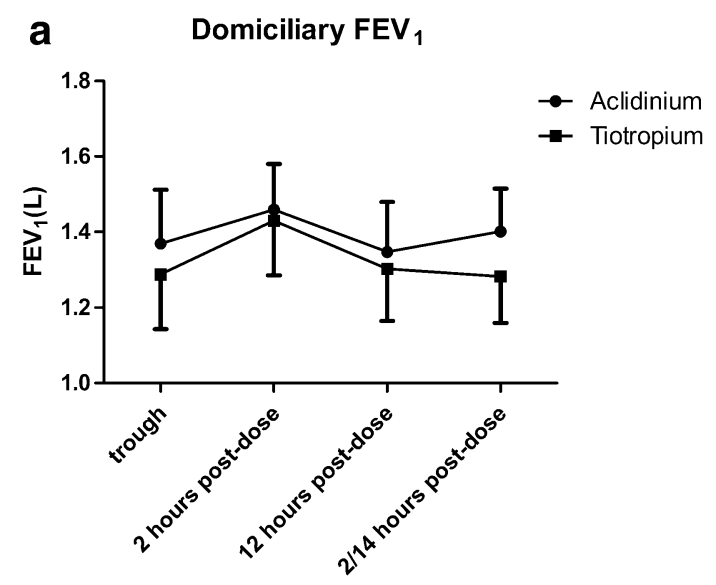

Fig. 5 Diurnal profiles with either tiotropium given once daily in the morning or aclidinium given twice daily in the morning and evening, for the last week of each randomized treatment. Data are depicted as means and SEM. a $F E V_{1}$ forced expiratory volume in $1 \mathrm{~s} \mathbf{b} F E V_{6}$ forced expiratory volume in $6 \mathrm{~s}$. Data are shown for the morning

salmeterol versus fluticasone/salmeterol/TIO for 2 weeks in patients with COPD, where the primary outcome of peak specific airway conductance (as AUC $0-4 \mathrm{~h}$ ) showed a $27 \%$ significant difference in favor of triple therapy, while for trough $\mathrm{FEV}_{1}$, there was a significant mean difference of $110 \mathrm{ml}$ [3]. In our study, we showed significant within treatment improvements in mean trough $\mathrm{FEV}_{1}$ amounting to $110 \mathrm{ml}$ with ACL and $150 \mathrm{ml}$ with $\mathrm{TIO}$, as compared to the minimal important difference of 100-140 $\mathrm{ml}$ [16] .

For visit-based spirometry outcomes including $\mathrm{FEV}_{1}$, FVC, and RVC we observed significant within treatment effects compared to baseline in response to TIO and ACL, but no difference between treatments. Moreover, there were no significant differences between treatments for domiciliary diurnal profiles of $\mathrm{FEV}_{1}$ and $\mathrm{FEV}_{6}$. In a previous comparison of the same doses of TIO and ACL used as monotherapy, there were no differences between drugs in terms of trough pre-dose $\mathrm{FEV}_{1}$ measurements after 2 weeks, although the AUC 12-24 h for the visit-based diurnal $\mathrm{FEV}_{1}$ profile was significantly better with ACL compared to TIO after chronic dosing [11]. This observed difference in the $\mathrm{FEV}_{1}$ AUC 12-24 $\mathrm{h}$ corresponds to the 12-h period after taking the evening dose of ACL when the effect of TIO is beginning to wane throughout the night time prior to the next morning dose. Perhaps on reflection, we might have also shown such differences in domiciliary $\mathrm{FEV}_{1}$ if we had performed diurnal evening measurements between the 14- and 24-h time point for TIO, although we considered that this was not practical for elderly patients to perform at home. Another possibility is that in the present study, there may be less room for further improvement conferred by LAMA when given as add-on to ICS/LABA compared to its use as monotherapy. In a previous comparison of TIO and GLYC as add-on to ICS/LABA, the

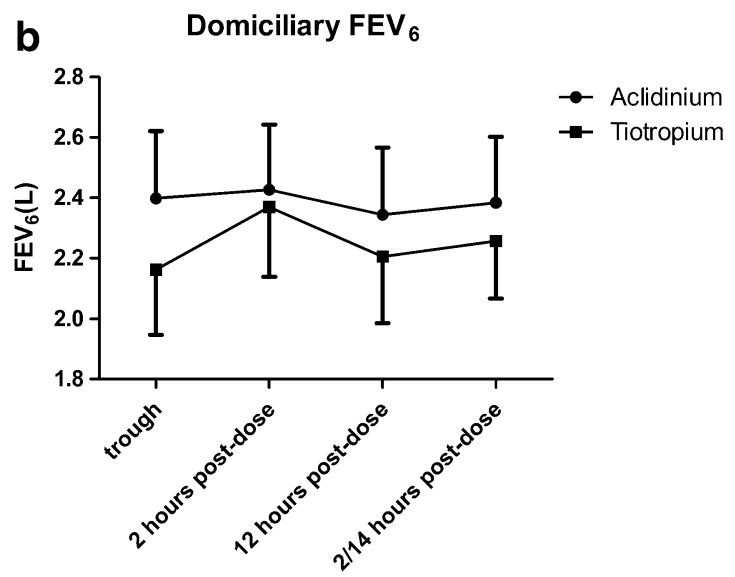

trough measurement (i.e., pre-dose for aclidinium and tiotropium), 2 and $12 \mathrm{~h}$ post dose (i.e., trough for aclidinium), and $2 \mathrm{~h}$ post the evening dose of aclidinium or $14 \mathrm{~h}$ after the morning dose of tiotropium. There were no significant differences between tiotropium and aclidinium at any time points

mean difference in the primary outcome of trough $\mathrm{FEV}_{1}$ amounted to $7 \mathrm{ml}$ [10], as compared to a $40 \mathrm{ml}$ difference between TIO and ACL in the present study.

We used dry powder formulations of TIO and ACL which emit coarse particles $>2 \mu \mathrm{m}$, which could also explain the somewhat limited improvements in pulmonary function. In this regard, we are not aware of any head to head lung deposition studies comparing TIO and ACL dry powder formulations in COPD. Perhaps using smaller particle formulations such as the fine-mist TIO Respimat inhaler might result in greater improvements in regional lung deposition.

With the development of single inhaler triple therapy, it will be important to know what the impact is on more clinically relevant outcomes. In a retrospective cohort study of 2853 patients with moderate to severe COPD followed up over 4.65 years, there were 996 receiving ICS/ LABA $\left(\mathrm{FEV}_{1}\right.$ of $\left.63 \%\right)$ and 1857 receiving ICS/LABA/ LAMA (FEV ${ }_{1}$ of $51 \%$ ) [17]. Comparing triple versus dual therapy, there was a $15 \%$ reduction in hospital admissions, $29 \%$ fewer oral corticosteroid bursts, and $26 \%$ lower allcause mortality, while triple therapy was associated with a fall in serial $\mathrm{FEV}_{1}$ of $30 \mathrm{ml}$ over 4 years.

Aside from pulmonary function outcomes, it is also important to consider the impact of treatment upon functional status (6-min walk distance and dyspnoea index) and health-related quality of life (SGRQ) [16]. While we observed no difference between treatments in 6-min walking distance, there was a $36 \mathrm{~m}$ mean improvement from baseline with ACL, which exceeds the minimal important difference of $25 \mathrm{~m}[18,19]$. There was a significant improvement post-walk fatigue with ACL and in post-walk dyspnoea with TIO, but no differences were seen in either outcome between treatments. Furthermore post- 
walk heart rate and oxygen saturation did not change with either treatment. In terms of quality of life, although the SGRQ symptoms score was significantly improved with both drugs, there was no difference between them. The transition dyspnoea index was significantly improved by ACL versus TIO by a mean difference of 1.54 which exceeded the minimal important difference of 1.0 [20]. The relevance of this finding in the absence of any differences in objective pulmonary function outcomes is uncertain.

In summary, we observed comparable bronchodilator efficacy at trough with TIO and ACL when used as triple therapy in COPD, while IOS was no more sensitive than spirometry. The utility of IOS measurements in COPD requires further evaluation perhaps using a diurnal IOS profile to compare with spirometry or whole-body plethysmography.

Acknowledgments We would like to thank Almirall for the unrestricted grant and supply of the ACL inhalers.

Funding This study was funded by an unrestricted grant from Almirall. Almirall did not have any role in the study design; in the collection, analysis and interpretation of data; in the writing of the report; and in the decision to submit the article for publication.

\section{Compliance with Ethical Standards}

Conflicts of interest The Scottish Centre for Respiratory Research has received an unrestricted Grant from Almirall to support the present study and from AstraZeneca for recruiting into a multicentre trial. BJL has received payments from Boehringer for consulting and attending advisory boards as well as support for attending the British Thoracic Society and European Respiratory Society and American Academy of Allergy Asthma and Immunology. AM and AEM have no conflicts of interest to declare.

Ethical Standards This manuscript complies with the current laws of the United Kingdom

Open Access This article is distributed under the terms of the Creative Commons Attribution 4.0 International License (http://crea tivecommons.org/licenses/by/4.0/), which permits unrestricted use, distribution, and reproduction in any medium, provided you give appropriate credit to the original author(s) and the source, provide a link to the Creative Commons license, and indicate if changes were made.

\section{References}

1. Vestbo J, Hurd SS, Agusti AG et al (2013) Global strategy for the diagnosis, management, and prevention of chronic obstructive pulmonary disease: GOLD executive summary. Am J Respir Crit Care Med 187(4):347-365

2. Gavalda A, Ramos I, Carcasona $C$ et al (2014) The in vitro and in vivo profile of aclidinium bromide in comparison with glycopyrronium bromide. Pulm Pharmacol Ther 28(2):114-121

3. Singh D, Brooks J, Hagan G, Cahn A, O'Connor BJ (2008) Superiority of "triple" therapy with salmeterol/fluticasone propionate and tiotropium bromide versus individual components in moderate to severe COPD. Thorax 63(7):592-598
4. Hanania NA, Crater GD, Morris AN, Emmett AH, O'Dell DM, Niewoehner DE (2012) Benefits of adding fluticasone propionate/ salmeterol to tiotropium in moderate to severe COPD. Respir Med 106(1):91-101

5. Jung KS, Park HY, Park SY et al (2012) Comparison of tiotropium plus fluticasone propionate/salmeterol with tiotropium in COPD: a randomized controlled study. Respir Med 106(3): 382-389

6. Welte T, Miravitlles M, Hernandez P et al (2009) Efficacy and tolerability of budesonide/formoterol added to tiotropium in patients with chronic obstructive pulmonary disease. Am J Respir Crit Care Med 180(8):741-750

7. Aaron SD, Vandemheen KL, Fergusson D et al (2007) Tiotropium in combination with placebo, salmeterol, or fluticasonesalmeterol for treatment of chronic obstructive pulmonary disease: a randomized trial. Ann Intern Med 146(8):545-555

8. Cazzola M, Ando F, Santus P et al (2007) A pilot study to assess the effects of combining fluticasone propionate/salmeterol and tiotropium on the airflow obstruction of patients with severe-tovery severe COPD. Pulm Pharmacol Ther 20(5):556-561

9. Williamson PA, Short PM, Clearie KL et al (2010) Paradoxical trough effects of triple therapy with budesonide/formoterol and tiotropium bromide on pulmonary function outcomes in COPD. Chest 138(3):595-604

10. Frith PA, Thompson PJ, Ratnavadivel R et al (2015) Glycopyrronium once-daily significantly improves lung function and health status when combined with salmeterol/fluticasone in patients with COPD: the GLISTEN study-a randomised controlled trial. Thorax 70(6):519-527

11. Fuhr R, Magnussen H, Sarem K et al (2012) Efficacy of aclidinium bromide $400 \mu \mathrm{g}$ twice daily compared with placebo and tiotropium in patients with moderate to severe COPD. Chest 141(3):745-752

12. Beier J, Kirsten AM, Mroz R et al (2013) Efficacy and safety of aclidinium bromide compared with placebo and tiotropium in patients with moderate-to-severe chronic obstructive pulmonary disease: results from a 6-week, randomized, controlled Phase IIIb study. COPD 10(4):511-522

13. Williamson PA, Clearie K, Menzies D, Vaidyanathan S, Lipworth BJ (2011) Assessment of small-airways disease using alveolar nitric oxide and impulse oscillometry in asthma and COPD. Lung 189(2):121-129

14. Anderson WJ, Lipworth BJ (2012) Relationships between impulse oscillometry, spirometry and dyspnoea in COPD. J R Coll Physicians Edinb 42(2):111-115

15. Crim C, Celli B, Edwards LD et al (2011) Respiratory system impedance with impulse oscillometry in healthy and COPD subjects: ECLIPSE baseline results. Respir Med 105(7): 1069-1078

16. Cazzola M, MacNee W, Martinez FJ et al (2008) Outcomes for COPD pharmacological trials: from lung function to biomarkers. Eur Respir J 31(2):416-469

17. Short PM, Williamson PA, Elder DH, Lipworth SI, Schembri S, Lipworth BJ (2012) The impact of tiotropium on mortality and exacerbations when added to inhaled corticosteroids and longacting beta-agonist therapy in COPD. Chest 141(1):81-86

18. Holland AE, Hill CJ, Rasekaba T, Lee A, Naughton MT, McDonald CF (2010) Updating the minimal important difference for six-minute walk distance in patients with chronic obstructive pulmonary disease. Arch Phys Med Rehabil 91(2):221-225

19. Puhan MA, Chandra D, Mosenifar $Z$ et al (2011) The minimal important difference of exercise tests in severe COPD. Eur Respir J 37(4):784-790

20. Witek TJ Jr, Mahler DA (2003) Minimal important difference of the transition dyspnoea index in a multinational clinical trial. Eur Respir J 21(2):267-272 